\title{
The combined effect of socioeconomic status and metabolic syndrome on depression: the Korean National Health and Nutrition Examination Survey (KNHANES)
}

Byungmi Kim

National Cancer Institute

Eun Young Park ( $\nabla$ goajoa@ncc.re.kr)

National Cancer Center https://orcid.org/0000-0003-4859-6782

Research article

Keywords: Social environment, metabolism, depression, mental health

Posted Date: April 28th, 2020

DOI: https://doi.org/10.21203/rs.3.rs-15603/v2

License: (ㅇ) (i) This work is licensed under a Creative Commons Attribution 4.0 International License. Read Full License

Version of Record: A version of this preprint was published at BMC Public Health on May 4th, 2020. See the published version at https://doi.org/10.1186/s12889-020-08778-3. 


\section{Abstract}

Background: Depression shows different patterns depending on socioeconomic status (SES) and metabolic syndrome (MS). However, the nature of this association remains poorly understood. The aim of this study was to examine whether the combination of MS and lower SES was associated with the prevalence of depression, based on data from the Korea National Health and Nutrition Examination Survey (KNHANES).

Methods: Data were obtained from a cross-sectional study of 24,102 adults (>19 years of age) who participated in the KNHANES during 2008-2013 and for whom MS and depression data were available. MS was defined using the diagnostic criteria of the modified National Cholesterol Education Program Adult Treatment Panel III. Measure of depression was ascertained from self-reports of physician diagnosis. Multiple logistic regression analysis was used to evaluate the association between depression and MS as well as SES (alone and in combination).

Results: Overall, 622 of the 24,102 subjects $(2.6 \%)$ met the criteria for depression. The prevalence of depression was associated with MS, a lower high-density lipoprotein cholesterol level, an elevated triglyceride level, a lower education level, and a lower household income. Participants with MS and a low SES had a higher likelihood of depression than those without MS and a high SES (odds ratio [OR]=4.180 for low education level and OR=3.994 for low household income level).

Conclusions: This study suggests that the combination of SES and MS may play an important role in depression, which has implications for healthcare policy and depression management.

\section{Background}

Depression is a common mood disorder, the prevalence of which increased during the 20th century [1]. Depression is especially associated with increased cardiovascular morbidity and all-cause mortality [2], and it may be linked to an elevated risk of poor health outcomes through its association with low socioeconomic status (SES) and metabolic syndrome (MS) [3]. However, little is understood about mechanisms that may account for adverse health outcomes associated with depression.

Previous reports have speculated that depression may be linked to adverse health outcomes through an association with the metabolic syndrome $[1,4,5]$. MS is a complex disorder characterized by a cluster of metabolic, anthropometric, and hemodynamic abnormalities. The National Cholesterol Education Program (NCEP) Adult Treatment Panel III (ATP III) [6] defined MS as the presence of at least three of the following: abdominal obesity, elevated triglyceride (TG) levels, decreased high-density lipoprotein cholesterol (HDL-C) levels, hypertension, and hyperglycemia. Previous studies have reported associations between depression and several MS components, including larger waist circumference $[1,3,7]$; higher levels of glucose $[7,8]$, blood lipids [9, 10], and TG [1, 3]; higher blood pressure (BP) [1, 11, 12]; and lower HDL-C levels [1, 3]. Accumulating evidence suggests that depression is not simply a comorbidity of MS. Instead, it has been suggested that the association between obesity and mood disorders represents a distinct condition known as metabolic-mood syndrome [13-16]. However, many questions remain unanswered regarding the above associations. 
Lower socioeconomic status (SES) is associated with higher odds of having depression [17-19]. Beset by growing national and international inequalities in socioeconomic status (SES) has come into focus as a significant determinant of depression [17]. The effect of SES on depression is an important theme, and this supports previous studies which illustrate the negative association between SES and depression [20-22]. In South Korea, the "Establish the National Health Plan 2020" project, published in 2011 [23], aimed to achieve health equity and promote health across all stages of life and reduce the gap in health status across different SES levels [24]. This is highly relevant because the incidences of both depression in Korea differ according to SES $[25,26]$. In a study of community dwellers on Jeju Island, South Korea [27], the prevalence of depressive symptoms differed according to monthly income and education status. Kahng and Kwon reported that individuals with a relatively low SES, such as those with a low income, low education level, and female sex, exhibited high levels of depression (Kang and Kwon, 2008)

Most previous studies focused on the relationship between MS and depression. However, the results of these studies were conflicting $[1,7,19]$, possibly because of differences in SES. Moreover, no published studies have explored the combined effects of SES and MS on depression. Therefore, the aim of this study was to examine whether the combination of SES and MS was associated with the prevalence of depression in Korean men and women who participated in the Korean National Health and Nutrition Examination Survey (KNHANES).

\section{Methods}

\section{Study population}

KNHANES is a cross-sectional survey of a nationally representative sample of the civilian, noninstitutionalized population in South Korea. This population-based survey has a multistage sampling design and includes three assessments: health interview, health examination, and nutrition survey. KNHANES has contributed to the development and evaluation of health policies and programs, facilitated the establishment of reference values (such as growth charts and dietary references) for the Korean population, and supported health research [28].

Data used in this study were derived from the 2008 to 2013 KNHANES data, which were stratified according to age, sex, and geographic area. We used data from the health interview and health examination. In total, 53,829 individuals participated in KNHANES from 2008 to 2013: 9,744 in 2008, 10,533 in 2009, 8,958 in $2010,8,518$ in $2011,8,058$ in 2012, and 8,018 in 2013. Study participants were at least 20 years of age. Of these, 26,393 subjects with missing data for depression $(n=472)$ or $M S(n=1,819)$ were excluded. The final study population therefore consisted of 24,102 adults.

All procedures contributing to this study complied with the ethical standards of the relevant national and institutional committees on human experimentation and with the Helsinki Declaration of 1975, as revised in 2008. All procedures involving human subjects were approved by the Korea Centers for Disease Control and Prevention Institutional Review Board, and all participants signed a written informed consent form.

\section{Data collection}


As previously described in detail [28], KNHANES is conducted by four specialized research teams, each of which consists of eight experts, including nurses, nutritionists, and students majoring in public health. The selected professional investigator was placed at the investigation site after completing 1 month of training and conducted interviews with participants using a structured questionnaire. The following information was collected: presence of physician-diagnosed hypertension, diabetes mellitus, stroke, heart disease (including myocardial infarction or angina), osteoporosis, osteoarthritis, and depression; current or previous back pain; medication for hypertension, diabetes mellitus, or hyperlipidemia; and sociodemographic and lifestyle data, including age, sex, marital status, education, household income, smoking status, alcohol consumption, and physical activity. Participants who smoked $<100$ cigarettes in their life were classified as never smokers; the remainder were categorized as current or former smokers. Individuals consuming $\geq 12$ alcohol-containing drinks per year were considered alcohol drinkers. Physical activity and history of chronic diseases were evaluated by yes or no responses to relevant questions. Participants were divided into monthly household income quartiles: low (1,200,000 won), medium (1,210,000-4,300,000 won), and high (>4,310,000 won). Participants were also classified by educational level: less than elementary school, middle school, high school, or college or more). The results of standardized health examinations conducted at local community health centers and clinics were used to obtain anthropometric data (height, weight, and waist circumference). Body mass index (BMI) was calculated as weight in kilograms divided by height in meters squared. Waist circumference was measured at the midpoint between the 12th rib and anterior iliac spine. $\mathrm{BP}$ was measured on the right arm using an automatic sphygmomanometer with participants in the sitting position, after resting for 5 minutes. Average systolic blood pressure (SBP) and diastolic blood pressure (DBP) values of at least two repeated measurements were calculated. Blood samples were collected after overnight fasting to measure fasting blood sugar (FBS), TG, total cholesterol, HDL-C, and high-sensitivity Creactive protein levels.

\section{Metabolic syndrome definition}

According to the revised NCEP ATP III [6] definition, a person may be diagnosed with MS when they meet three or more of these criteria: 1) abdominal obesity, determined by a large waist circumference ( $>90 \mathrm{~cm}$ for men; > $80 \mathrm{~cm}$ for women), according to the International Obesity Task Force criteria for the Asia-Pacific population [29][28][28][27]; 2) TG level $\geq 150 \mathrm{mg} / \mathrm{dL}$ or use of medication to reduce TG levels;3) low HDL-C ( $<40 \mathrm{mg} / \mathrm{dL}$ for males; $<50 \mathrm{mg} / \mathrm{dL}$ for females) or use of medication for hypercholesterolemia; 4) hypertension (SBP $\geq 130 \mathrm{~mm} \mathrm{Hg}$ or DBP $>85 \mathrm{~mm} \mathrm{Hg}$ ) or use of antihypertensive medication; or 5) FBS $\geq$ $100 \mathrm{mg} / \mathrm{dL}$ or use of medication for hyperglycemia.

\section{Assessment of depression}

As described in detail previously [30], depression was measured using these two screening questions, for which "yes" or "no" answers were solicited: 1) "In your lifetime, have you ever had depression?" and 2) "Have you ever been diagnosed with depression by a physician?" If the response to the second question was yes, the age at first depression diagnosis was solicited. Based on these questions, we defined two outcome measures for depression: (1) self-reported depression and (2) self-reported physician-diagnosed depression. For statistical analysis, depression was defined as the presence of either of these two outcomes. 


\section{Statistical analysis}

KNHANES data were combined for all years from 2008 to 2013. Descriptive data are presented as weighted means or percentages with standard errors. Multiple logistic regression analysis for a complex sampling design was performed using PROC SURVEYLOGISTIC in SAS to evaluate the association between depression and SES, as well as MS (alone and in combination). Model 1 was adjusted for age (year, continuous) and sex. Model 2 was adjusted for sex, age, education level (less than elementary school, middle school, high school, or college or more), household income (low, middle, or high), marital status (married, unmarried, or divorced/widowed/separated), physical activity (yes or no), smoking status, alcohol consumption (non-drinker, $\leq 2-4$ times/month, 2-3 times/week, or $\geq 4$ times/week), and chronic disease status (yes or no). Model 3 added history of depression as a covariate and included the confounding variables of model 2. Combined effects represent the combination of SES level and MS, with SES defined by education level or household income. The following eight groups were defined according to education level and the presence or absence of MS: 1) college or more without MS, 2) college or more with MS, 3) high school without MS, 4) high school with MS, 5) middle school without MS, 6) middle school without MS, 7) less than elementary school without MS, and 8) less than elementary school with MS. Similarly, the following five groups were defined according to household income and the presence or absence of MS: 1) high income without MS, 2) high income with MS, 3) middle income without MS, 4) middle income with MS, 5) low income without MS, and 6) low income with MS. We also examined whether the combination of SES and MS was associated with the prevalence of depression in men and women. Data analyses were performed using SAS version 9.3 software with a survey procedure (SAS Institute, Inc., Cary, NC). Statistical significance was defined as a value of $p<0.05$.

\section{Results}

Table 1 shows the descriptive characteristics of the study population, as well as the risk (odds ratios [OR] and $95 \%$ confidence intervals [95\% $\mathrm{Cl}]$ ) of depression according to these characteristics. Depression was identified in 622 of the 24,102 subjects, representing a $2.6 \%$ prevalence of depression. Compared to the subgroup of participants with depression, the overall population were more likely to be older and married, have a higher education level and household income, and not have a physician-diagnosed history of depression. In contrast, participants with depression were more likely to be female and non-drinkers of alcohol; be divorced/widowed/separated; and have at least one chronic disease. The prevalence of MS was $20.1 \%$ in the overall population and $3.2 \%$ in participants with depression. The overall population was more likely to have an elevated TG level and lower FBS, whereas participants with depression were more likely to have a lower HDL-C and larger waist circumference.

ORs for depression decreased with increasing SES (Table 1). ORs for depression according to education level were $6.62(95 \% \mathrm{Cl} 4.94-8.88)$ for elementary school or less, 4.144 ( $95 \% \mathrm{Cl} 2.99-5.74)$ for middle school, and 2.12 (95\% $\mathrm{Cl} 1.63-2.77$ ) for high school, compared with college or more as the reference (OR 1.0). ORs for depression according to household income level were 4.87 (95\% $\mathrm{Cl} 3.58-6.62)$ for low income and 1.71 (95\% $\mathrm{Cl} 1.33-2.20)$ for middle income, compared with high income as the reference. Participants with MS had a higher prevalence of depression than those without MS. MS $(\mathrm{OR}=1.70)$, larger waist 
circumference $(\mathrm{OR}=1.83)$, higher HDL-C $(\mathrm{OR}=1.85)$, and higher FBS $(\mathrm{OR}=1.37)$ were all associated with depression. BP was not associated with depression.

Table 2 presents the results of logistic regression analyses of the association between depression and MS, each MS component, education level, and household income, after controlling for sex, age, education level, income, marital status, physical activity, smoking status, alcohol consumption, and chronic disease (model 2). MS was associated with an increased likelihood of depression ( $\mathrm{OR}=1.34,95 \% \mathrm{Cl} 1.05-1.72)$. Additionally, two MS components were significantly associated with an increased likelihood of depression: lower HDL-C (OR=1.40, 95\% $\mathrm{Cl} 1.12-1.74)$ and higher TG $(\mathrm{OR}=1.35,95 \% \mathrm{Cl} 1.06-1.71)$. There was also a non-statistically significant trend toward an association between depression and a larger waist circumference (OR=1.21, 95\% $\mathrm{Cl} 0.92-1.60)$ and higher FBS (OR=1.23, 95\% $\mathrm{Cl} 0.95-1.58)$, but no association was detected between BP and depression. Similar results were observed in model 3 (adjusted for the confounding factors of model 2 and a history of depression). Household income and education level were inversely associated with depression in all models $(p<0.0001)$.

To compare the association between depression and MS, MS components, and SES in males and females, logistic regression analyses with adjustment for confounding variables were performed (Table 3). Household income and education level were inversely associated with depression in both sexes. Among females, MS was associated with depression in all models. Two MS components were associated with an increased likelihood of depression in females but not in males: larger waist circumference and lower HDL-C. We also found that in females, the interaction term for education level and MS was significant, whereas the interaction term for household income level and MS was not significant; neither interaction term was significant in males (data not shown).

ORs for depression for the combination of SES (household income or education level) and MS are shown in Fig. 1. After adjusting for covariates, the OR for depression was 4.18 ( $95 \% \mathrm{Cl} 2.36-6.75)$ for the combination of low education level (elementary school or less) and MS, compared with high education level (college or more) and no MS as the reference (model 3). Similarly, the OR for depression was $4.00(95 \% \mathrm{Cl}$ 2.36-6.75) for the combination of low household income and MS, compared with high household income and no MS as the reference (model 3). In all models, the combination of lower SES (household income or education level) and MS was associated with the presence of depression. Furthermore, the combination of education level and MS was more strongly associated with depression in males than in females, as represented by higher ORs (Table 4).

\section{Discussion}

We found that SES and MS, both alone and in combination, were associated with the prevalence of depression. Lower SES increased the prevalence of depression, and this relationship was strongest among individuals with the lowest level of education or household income. MS and two MS components (lower HDL-C and higher TG) were significantly associated with an increased likelihood of depression, after adjusting for other potential risk factors. There was also a trend toward a positive association between depression and two other MS components (increased waist circumference and FBS). Additionally, 
participants with the combination of MS and lower SES had an increased the prevalence of depression, when compared with individuals with a higher SES and no MS.

Previous studies reported that depression is more prevalent among people with a lower SES [19, 31-33]. Our results are in agreement with these observations. Data from the Alameda County Study, a community-based longitudinal study of psychological and social factors and their role in health and well-being in almost 7,000 adults from Alameda County, California, demonstrated a graded relationship between SES and both prevalent and incident depression [34]. Among participants who were not depressed at the beginning of the study, those with low education (0-8 years) were increase risk when compared with those who have 12 years or more of education $(\mathrm{OR}=1.86,95 \% \mathrm{Cl} 1.36-2.55)$. [35]. In another the Alameda County Study, which defined SES by household income tertiles, yielded results similar to ours: $19 \%$ of lower-income respondents reported numerous depressive symptoms, but only approximately $11 \%$ of higher-income respondents reported these symptoms [34]. A meta-analysis evaluating socioeconomic inequality in depression noted that low-SES individuals had an elevated the prevalence of depression ( $\mathrm{OR}=1.81,95 \% \mathrm{Cl} 1.57-2.10)$ [19]. These findings suggest lower SES may be associated with risks of depression and should be considered a major risk factor for depression.

Our results also showed an association between depression and MS. These findings are consistent with those of previous studies [5, 36-38]. A longitudinal study found that participants with MS at baseline were 2fold more likely to develop depressive symptoms during follow-up than healthy matched controls [5]. In a cohort of healthy middle-aged females in the Healthy Women Study, MS predicted the development of depressive symptoms over a 6-year follow-up period [36]. In another population-based study, females with MS during childhood had higher levels of depressive symptoms in adulthood, and the severity of these symptoms increased in proportion to the duration of MS [37]. In 5,698 individuals from the Northern Finland 1966 Birth Cohort Study, MS was not associated with depression when assessed at the age of 31 years [39]. We also found that depression was associated with several MS components (waist circumference, HDL-C, TG, and FBS), although only the associations with lower HDL-C and higher TG remained significant after controlling for covariates in logistic regression analysis. Several previous studies evaluated associations between MS components and depression $[3,36,38]$. The Netherlands Study of Depression and Anxiety found that higher Inventory of Depressive Symptomatology scores were associated with a higher number of MS-related abnormalities, larger waist circumference, higher HDL-C, higher TG, and lower SBP [3]. Of five MS components evaluated in a study conducted in the United Kingdom, central obesity, high TG, and low HDL-C were predictive of depressive symptoms [36]. In a study from India, waist circumference was positively correlated with the severity of depressive symptoms measured using the Hamilton Depression Rating scale $(r=0.291, p=0.003)$ [38]. Whether MS components are more predictive of depression than MS itself is unclear [40]. Further research is required to confirm our findings and define the role of MS components as risk factors for depression.

In the present study, we found that the risk of depression was 4-fold higher among participants with MS and a lower SES than in those without MS and a higher SES. We observed similar trends in all three models. Two previous studies reported the prevalence of depression and its comorbidities according to SES [41, 42]. In the MultiCare Cohort Study, lower SES was associated with a higher prevalence of chronic conditions, such 
as cardiovascular and metabolic disorders (CMDs), as well as the composite outcome of depression, anxiety, somatoform disorders, and pain. The number of CMDs was associated with the level of education (-0.17 CMDs for medium level and -0.26 CMDs for high level, when compared with a low education level) and income (-0.27 CMDs per unit on a logarithmic scale). SES of patients with CMDs was inversely related to the prevalence of depression in both males and females, although the association was stronger in females [41]. In the other study, which was a population-based study of adult females in the United States Buffalo-Niagara region, the prevalence of depression plus obesity was higher in more educated women than in less educated women $(\mathrm{OR}=2.15,95 \% \mathrm{Cl}$ 1.27-3.62) [42]. By contrast, the combination of education level and MS was more strongly associated with depression in males than in females in our study. These findings suggest the existence of important sex differences for the combined role of education level and MS on the development of depression. It is also possible that men underestimate their negative affective states because of differences in cognitive appraisal, accessibility of memories, or reliance on implicit beliefs, stereotypes, or cultural differences [43]. This, in turn, may mask the true nature of the associations between SES, MS and depression. Sex differences in the association between SES, MS and depression may also have physiological mechanisms, but this requires further investigation [7]. Numerous studies have reported the prevalence of depression among participants with a lower SES or MS [19, 31-35]. However, little is known about the combined effects of SES and MS on depression. To our knowledge, there have been no previous reports regarding the association between depression and the combination of SES and MS.

The current study suggests that SES and MS are an important factor in depression, however, the mechanism underlying its role remains unclear. The relation between SES and MS on depression may be at least partly explained by autonomic nervous system changes. In animal models, neuroendocrine system responses to SES have included hyperexcitation of the sympathetic system, hypersecretion of cortisol, and increased visceral fat. These changes are similar to those found in MS, and they have been suggested to occur in depression as well [44]. Furthermore, subordinate rats (which are a model for social stress, as may occur in humans with a low SES) have elevated levels of plasma insulin and leptin and display overeating behavior $[26,45]$. Depression has also been associated with changes in inflammatory and hemostatic markers, including increased platelet aggregation, fibrinogen levels, and white blood cell counts $[1,46,47]$. As inflammatory and hemostatic processes also play important roles in MS, depression may be linked to MS and its components through these processes [1]. Further research in this area is warranted.

The present study had some limitations. First, we were unable to determine whether there is a causal relationship between depression and MS and/or low SES, because of the study's cross-sectional design. Prospective studies are required to establish whether a causal relationship exists. Second, information bias was unavoidable because the study was based on a questionnaire. Third, the presence of depression was based on self-reported data. However, the lifetime prevalence of self-reported depression (2.6\%) in this population was similar to the $2.7 \%$ prevalence reported in a previous Korean study in which depression was assessed using a well-validated questionnaire [48]. Our findings should be verified using more comprehensive assessments of depression. Fourth, our focus on five metabolic factors may represent an oversimplification of the extremely complex pathophysiologic processes leading to atherosclerosis. High cholesterol and BP may interact synergistically with other, non-conventional risk factors in the development of atherosclerosis. 
Despite these limitations, this study has several strengths, including the use of data from a large population of apparently healthy subjects with a low prevalence of chronic disease $(92.8 \%$ of the overall study population had no chronic disease). Additionally, because of considerable variation in MS components among individuals, we were able to analyze various MS components, in addition to MS itself. Finally, this study included an assessment of several variables, such as disease history, health behavior, education, and household income, as well as the interaction between SES and MS.

In conclusion, this study showed that SES and MS, both alone and in combination, were associated with the prevalence of depression. Our findings indicate the importance of the combined effect of SES and MS in depression. It remains a task of future research to determine whether the combination of SES and MS was associated with the prevalence of depression across various populations. An in-depth understanding of the combination of SES and MS that are present in individuals with depression can provide basic data that would help to public health strategies for reduce the prevalence of depression.

\section{Abbreviation}

KNHANES: the Korean National Health and Nutrition Examination Survey; SES: Socioeconomic Status; MS: Metabolic Syndrome; NCEP: National Cholesterol Education Program; ATP III: Adult Treatment Panel III; TG: Triglyceride: HDL-C: High-density lipoprotein Cholesterol; BP: Blood Pressure; BMI: Body mass index; SBP: Systolic Blood Pressure; DBP: Diastolic Blood Pressure; FBS: Fasting Blood Sugar; OR: Odds ratios; $95 \%$ Cl: 95\% confidence intervals; CMD: metabolic disorders

\section{Declarations}

\section{Ethics approval and consent to participate}

The KNHANES was approved by the Institutional Review Board of the Korea Centers for Disease Control (IRB No. 1401-047-547), and all participants signed an informed consent form. This study meets the Helsinki Declaration-based ethical principles for medical research involving human subjects.

\section{Consent for publication}

Not applicable.

\section{Availability of data and materials}

All data files are available from the Korea Centers for Disease Control and Prevention database through the following URL: https://knhanes.cdc.go.kr/knhanes/sub03/sub03_02_02.do. Any person, including an international researcher who signs up for membership, can obtain raw data from this website. However, the data access process and user manual are only written in Korean.

\section{Competing interests}

The authors declare that they have no competing interests. 


\section{Funding}

None received for the study

\section{Authors' contributions}

B.K contributed to the discussion, interpreted the results, and wrote the manuscript. E.Y.P. developed the study plan, contributed to the discussion, and reviewed and edited the manuscript. All authors gave important intellectual contributions, reviewed the manuscript, and provided final consent of the version to be published. B.K and E.Y.P. are guarantors of this work and, as such, had full access to all study data and take responsibility for the integrity of the data and accuracy of the data analysis.

\section{Acknowledgements}

We would like to thank all respondents who participated in the Korean National Health and Nutrition Examination Survey (KNHANES).

\section{References}

1. Kinder LS, Carnethon MR, Palaniappan LP, King AC, Fortmann SP: Depression and the Metabolic Syndrome in Young Adults: Findings From the Third National Health and Nutrition Examination Survey. Psychosom Med. 2004;66(3):316-22.

2. Kozela M, Bobak M, Besala A, Micek A, Kubinova R, Malyutina S, et al: The association of depressive symptoms with cardiovascular and all-cause mortality in Central and Eastern Europe: Prospective results of the HAPIEE study. Eur J Prev Cardiol. 2016;23(17):1839-47

3. Hiles SA, Revesz D, Lamers F, Giltay E, Penninx BW: Bidirectional prospective associations of metabolic components with depression, anxiety, and antidepressant use. Depress Anxiety. 2016;33(8):754-64.

4. Chrousos GP. The role of stress and the hypothalamic-pituitary-adrenal axis in the pathogenesis of the metabolic syndrome: neuro-endocrine and target tissue-related causes. Int J Obes Relat Metab Disord. 2000;24(2):S50-5.

5. Koponen H, Jokelainen J, Keinanen-Kiukaanniemi S, Kumpusalo E, Vanhala M. Metabolic syndrome predisposes to depressive symptoms: a population-based 7-year follow-up study. J Clin Psychiatry 2008, 69(2):178-182.

6. Grundy SM, Cleeman JI, Daniels SR, Donato KA, Eckel RH, Franklin BA, et al. Diagnosis and management of the metabolic syndrome: an American Heart Association/National Heart, Lung, and Blood Institute scientific statement: Executive Summary. Crit pathw cardiol. 2005;4(4):198-203.

7. Toker S, Shirom A, Melamed S. Depression and the metabolic syndrome: gender-dependent associations. Depress Anxiety. 2008;25(8):661-669.

8. Weber B, Schweiger U, Deuschle M, Heuser I. Major depression and impaired glucose tolerance. Exp Clin Endocrinol Diabetes. 2000;108(3):187-90. 
9. Rowan PJ, Haas D, Campbell JA, Maclean DR, Davidson KW. Depressive symptoms have an independent, gradient risk for coronary heart disease incidence in a random, population-based sample. Ann epidemiol. 2005;15(4):316-20.

10. Nakao M, Ando K, Nomura S, Kuboki T, Uehara Y, Toyooka T, et al. Depressive mood accompanies hypercholesterolemia in young Japanese adults. Jap heart j. 2001;42(6):739-48.

11. Scherrer JF, Xian H, Bucholz KK, Eisen SA, Lyons MJ, Goldberg J, et al. A twin study of depression symptoms, hypertension, and heart disease in middle-aged men. Psychosom Med. 2003;65(4):548-57.

12. Davidson K, Jonas BS, Dixon KE, Markovitz JH. Do depression symptoms predict early hypertension incidence in young adults in the CARDIA study? Coronary Artery Risk Development in Young Adults. Arch intern med. 2000;160(10):1495-500.

13. McIntyre RS, Soczynska JK, Konarski JZ, Woldeyohannes HO, Law CW, Miranda A, et al. Should Depressive Syndromes Be Reclassified as "Metabolic Syndrome Type II"? Ann Clin Psychiatry. 2007;19(4):257-264.

14. Mansur RB, Brietzke E, Mclntyre RS. Is there a "metabolic-mood syndrome"? A review of the relationship between obesity and mood disorders. Neurosci \& Biobehav Rev. 2015;52:89-104.

15. Vogelzangs N, Beekman AT, Boelhouwer IG, Bandinelli S, Milaneschi Y, Ferrucci L, et al. Metabolic depression: a chronic depressive subtype? Findings from the InCHIANTI study of older persons. J Clin Psychiatry. 2011;72(5):598-604.

16. Levitan RD, Davis C, Kaplan AS, Arenovich T, Phillips DI, Ravindran AV. Obesity comorbidity in unipolar major depressive disorder: refining the core phenotype. J Clin Psychiatry. 2012;73(8):1119-1124.

17. Freeman A, Tyrovolas S, Koyanagi A, Chatterji S, Leonardi M, Ayuso-Mateos JL, et al. The role of socioeconomic status in depression: results from the COURAGE (aging survey in Europe). BMC Public Health. 2016;16(1):1098.

18. Lorant V, Deliège D, Eaton W, Robert A, Philippot P, Ansseau M. Socioeconomic Inequalities in Depression: A Meta-Analysis. Am J Epidemiol. 2003;157(2):98-112.

19. Lorant V, Deliège D, Eaton W, Robert A, Philippot P, Ansseau M. Socioeconomic Inequalities in Depression: A Meta-Analysis. Am J Epidemiol. 2003;157(2):98-112.

20. Jo SJ, Yim HW, Bang MH, Lee MO, Jun TY, Choi JS, et al. The Association between Economic Status and Depressive Symptoms: An Individual and Community Level Approach. Psychiatry Investig. 2011;8(3):194-200.

21. WHO International Consortium in Psychiatric Epidemiology. Cross-national comparisons of the prevalences and correlates of mental disorders. WHO International Consortium in Psychiatric Epidemiology. Bull World Health Organ. 2000;78(4):413-26.

22. Muntaner C, Eaton WW, Miech R, O'Campo P. Socioeconomic position and major mental disorders. Epidemiol rev. 2004;26:53-62.

23. Ministry for Health WaFA. Health Plan 2010 Leading Health Indicator \& Plans. Gwacheon: Ministry for Health, Welfare and Family Affairs. Korea; 2011. 
24. Affairs KIfHaS: Establish of new health plan 2010. Seoul: Korea Institute for Health and Social Affairs. In.; 2006.

25. Health TKSfEi: Methods in health inequalities measurement. In. Paju: Hanul Publishing Co.; 2008.

26. Kim JY, Kim SH, Cho YJ: Socioeconomic status in association with metabolic syndrome and coronary heart disease risk. Korean Journal of Family Medicine. 2013;34(2):131-38.

27. Kim MD, Hong SC, Lee Cl, Kwak YS, Shin TK, Jang YH, et al. Prevalence of depression and correlates of depressive symptoms for residents in the urban part of Jeju Island, Korea. Int J Soc Psychiatry. 2007;53(2):123-34.

28. Kweon S, Kim Y, Jang MJ, Kim Y, Kim K, Choi S, et al. Data resource profile: the Korea National Health and Nutrition Examination Survey (KNHANES). International Journal of Epidemiology. 2014;43(1):6977.

29. World Health Organization western pacific region. The Asia-Pacific Perspective Redefining Obesity and its Treatment. IASO international association for the study of obesity. WHO, 2000.

30. Park RJ, Moon JD. Coffee and depression in Korea: the fifth Korean National Health and Nutrition Examination Survey. Eur J Clin Nutr. 2015;69(4):501-4.

31. Ladin K. Risk of late-life depression across 10 European Union countries: deconstructing the education effect. J Aging Health. 2008;20(6):653-670.

32. Bruce ML, Takeuchi DT, Leaf PJ. Poverty and psychiatric status. Longitudinal evidence from the New Haven Epidemiologic Catchment Area study. Arch Gen psychiatry. 1991; 48(5):470-74.

33. Stansfeld SA, Marmot MG. Social class and minor psychiatric disorder in British Civil Servants: a validated screening survey using the General Health Questionnaire. Psychological medicine. 1992;22(3):739-49.

34. Berkman LF BL. Health and ways of living: the Alameda County Study. New York. Oxford University Press; 1983.

35. Kaplan GA, Roberts RE, Camacho TC, Coyne JC. Psychosocial predictors of depression. Prospective evidence from the human population laboratory studies. Am J Epidemiol. 1987;125(2):206-20.

36. Akbaraly TN, Kivimaki M, Brunner EJ, Chandola T, Marmot MG, Singh-Manoux A, et al. Association between metabolic syndrome and depressive symptoms in middle-aged adults: results from the Whitehall II study. Diabetes Care. 2009;32(3):499-504.

37. Pulkki-Raback L, Elovainio M, Kivimaki M, Mattsson N, Raitakari OT, Puttonen S, et al. Depressive symptoms and the metabolic syndrome in childhood and adulthood: a prospective cohort study. J Health Psychol. 2009;28(1):108-16.

38. Agarwal A, Agarwal M, Garg K, Dalal PK, Trivedi JK, Srivastava JS: Metabolic syndrome and central obesity in depression: A cross-sectional study. Indian J Psychiatry. 2016;58(3):281-6.

39. Herva A, Rasanen P, Miettunen J, Timonen M, Laksy K, Veijola J, et al. Co-occurrence of metabolic syndrome with depression and anxiety in young adults: the Northern Finland 1966 Birth Cohort Study. Psychosom med. 2006;68(2):213-6. 
40. Marazziti D, Rutigliano G, Baroni S, Landi P, Dell'Osso L. Metabolic syndrome and major depression. CNS Spectr. 2014;19(4):293-304.

41. Schafer I, Hansen H, Schon G, Hofels S, Altiner A, Dahlhaus A, et al. The influence of age, gender and socio-economic status on multimorbidity patterns in primary care. First results from the multicare cohort study. BMC Health Serv Res. 2012; doi: 10.1186/1472-6963-12-89.

42. Kranjac AW, Nie J, Trevisan M, Freudenheim JL. Depression and body mass index, differences by education: Evidence from a population-based study of adult women in the U.S. Buffalo-Niagara region. Obes Res Clin Pract. 2017.11(1):63-71.

43. Madden TE F-BL, Pietromonaco PR. Sex differences in anxiety and depression: Empirical evidence and methodological questions. In: Fischer AH, editor. Gender and emotion: social psychological perspectives. Cambridge: Cambridge University press; 2000. p. 277-298.

44. Tamashiro KL, Nguyen MM, Sakai RR. Social stress: from rodents to primates. Front Neuroendocrinol. 2005;26(1):27-40.

45. Neitzke U, Harder T, Plagemann A. Intrauterine growth restriction and developmental programming of the metabolic syndrome: a critical appraisal. Microcirculation (New York, NY : 1994). 2011;18(4):304-11.

46. Rozanski A, Blumenthal JA, Kaplan J. Impact of psychological factors on the pathogenesis of cardiovascular disease and implications for therapy. Circulation. 1999;99(16):2192-217.

47. Appels A, Bar FW, Bar J, Bruggeman C, de Baets M. Inflammation, depressive symptomtology, and coronary artery disease. Psychosom Med. 2000;62(5):601-5.

48. Kang SK, Kwon TY. An exploratory study on the effects of socioeconomic status on depressive symptoms across lifespan Ment Health Soc Work. 2008;30:332-55.

\section{Tables}

Table 1 Prevalence and odds ratio for being depression by general characteristics of study population with metabolic syndrome 


\begin{tabular}{|c|c|c|c|c|}
\hline \multirow[t]{2}{*}{ Characteristics } & \multicolumn{4}{|c|}{ Prevalence of depression } \\
\hline & $\begin{array}{c}\text { Total (weighted \%) } \\
n=24102(100.0)\end{array}$ & $\begin{array}{c}\text { Yes (weighted \%) } \\
n=622(2.6)\end{array}$ & OR(95\% CI) & $p$-value \\
\hline \multicolumn{5}{|l|}{ Gender } \\
\hline Male & $10228(51.0)$ & $128(1.2)$ & 1.00 & \multirow[t]{2}{*}{$<.0001$} \\
\hline Female & $13874(49.0)$ & $494(3.2)$ & $2.80(2.30-3.51)$ & \\
\hline \multicolumn{5}{|l|}{ Age group (years) } \\
\hline $19-29$ & $4369(24.3)$ & $79(1.5)$ & 1.00 & \multirow[t]{4}{*}{$<.0001$} \\
\hline $30-39$ & $6616(26.0)$ & $132(1.7)$ & $1.11(0.80-1.54)$ & \\
\hline $40-49$ & $6643(27.3)$ & $166(2.4)$ & $1.57(1.14-2.15)$ & \\
\hline $50-59$ & 6474(22.4) & $245(3.3)$ & $2.19(1.63-2.96)$ & \\
\hline \multicolumn{5}{|l|}{ Education level } \\
\hline College or more & $9269(38.1)$ & $114(1.0)$ & 1.00 & \multirow[t]{4}{*}{$<.0001$} \\
\hline High school & $10259(45.1)$ & $249(2.1)$ & $2.12(1.63-2.77)$ & \\
\hline Middle schools & $2312(8.9)$ & $104(4.0)$ & $4.14(2.99-5.74)$ & \\
\hline Elementary school or less & $2236(7.8)$ & $154(6.3)$ & $6.62(4.94-8.88)$ & \\
\hline \multicolumn{5}{|l|}{ House income } \\
\hline High & $8260(33.2)$ & $132(1.3)$ & 1.00 & \multirow[t]{3}{*}{$<.0001$} \\
\hline Middle & $13531(57.9)$ & $340(2.1)$ & $1.71(1.33-2.20)$ & \\
\hline Low & $2041(9.0)$ & $142(5.8)$ & $4.87(3.58-6.62)$ & \\
\hline \multicolumn{5}{|l|}{ Marital status } \\
\hline Married & $17775(68.0)$ & $407(2.0)$ & 1.00 & \multirow[t]{3}{*}{$<.0001$} \\
\hline Unmarried & $4860(26.6)$ & $94(1.6)$ & $0.82(0.63-1.08)$ & \\
\hline Divorced/Widowed/separated & $1419(5.4)$ & $119(7.4)$ & $3.93(3.06-5.05)$ & \\
\hline \multicolumn{5}{|l|}{ Body mass index } \\
\hline $18.5-22.9$ & $10096(41.3)$ & $229(1.9)$ & 1.00 & \multirow[t]{3}{*}{0.03} \\
\hline$<18.5$ & $1163(5.0)$ & $32(1.9)$ & $1.01(0.65-1.57)$ & \\
\hline$\geq 23.0$ & $12793(53.7)$ & $360(2.4)$ & $1.26(1.03-1.53)$ & \\
\hline \multicolumn{5}{|l|}{ Smoking status } \\
\hline non-smokers & $14261(53.1)$ & $393(2.3)$ & 1.00 & \multirow[t]{3}{*}{0.02} \\
\hline$<5$ pack & $727(3.4)$ & $27(3.5)$ & $1.49(0.96-2.34)$ & \\
\hline$\geq 5$ pack & $9074(43.5)$ & $199(1.9)$ & $0.79(0.65-0.94)$ & \\
\hline \multicolumn{5}{|l|}{ Alcohol consumption } \\
\hline Non-drinkers & $4830(17.6)$ & $191(3.7)$ & 1.00 & 0.003 \\
\hline$\leq 2-4$ times/month & $13772(57.5)$ & $328(2.0)$ & $0.53(0.43-0.66)$ & \\
\hline 2-3times/week & $3990(18.2)$ & $66(1.5)$ & $0.39(0.28-0.54)$ & \\
\hline$\geq 4$ times/week & $1424(6.6)$ & $36(2.0)$ & $0.55(0.37-0.81)$ & \\
\hline Physical activity & & & & \\
\hline No & 18558(76.9) & $476(2.2)$ & 1.00 & 0.39 \\
\hline Yes & $5509(23.1)$ & $144(2.0)$ & $0.91(0.73-1.13)$ & \\
\hline History of depression diagnosed & y a doctor & & & \\
\hline No & $23312(96.9)$ & $283(0.9)$ & 1.00 & $<.0001$ \\
\hline Yes & $790(3.1)$ & $339(41.4)$ & $1.71(1.38-2.10)$ & \\
\hline Prevalence of chronic diseases & & & & \\
\hline No & $22026(92.8)$ & $464(1.8)$ & 1.00 & $<.0001$ \\
\hline Yes & $2076(7.2)$ & $158(6.7)$ & $3.81(3.02-4.82)$ & \\
\hline Metabolic syndrome & & & & \\
\hline No & $19175(79.9)$ & $447(1.9)$ & 1.00 & $<.0001$ \\
\hline Yes & $4927(20.1)$ & $175(3.2)$ & $1.70(1.38-2.11)$ & \\
\hline Waist circumference $(\mathrm{cm})$ & & & & \\
\hline$<90$ (<80 for women) & $16956(72.2)$ & $348(1.8)$ & 1.00 & $<.0001$ \\
\hline$\geq 90$ ( $\geq 80$ for women) & $7146(27.8)$ & 274(3.2) & $1.83(1.51-2.22)$ & \\
\hline Triglyceride level (mg/dL) & & & & \\
\hline$<150$ & $17771(72.8)$ & $437(2.0)$ & 1.00 & 0.01 \\
\hline$\geq 150$ & 6331( & $185(2.7)$ & $1.34(1.078-1.66)$ & \\
\hline Blood pressure ${ }^{*}$ & & & & \\
\hline Normal & $18804(77.6)$ & $498(2.2)$ & 1.00 & 0.28 \\
\hline Abnormal & $5298(22.4)$ & $124(2.0)$ & $0.88(0.69-1.11)$ & \\
\hline HDL cholesterol level (mg/dL) & & & & \\
\hline$\geq 40$ ( $\geq 50$ for women) & $14539(62.9)$ & $297(1.7)$ & 1.00 & $<.0001$ \\
\hline$<40$ (<50 for women) & 9563(37.1) & $325(3.1)$ & $1.85(1.53-2.24)$ & \\
\hline
\end{tabular}




\begin{tabular}{lcccc} 
FBS $(\mathrm{mg} / \mathrm{dL})$ & & & \\
$<100$ & $18811(78.4)$ & $460(2.0)$ & 1.00 & 0.01 \\
$\geq 100$ & $5291(21.6)$ & $162(2.8)$ & $1.37(1.10-1.72)$ & \\
\hline
\end{tabular}

Normal: systolic $<130 \mathrm{mmHg}$ and diastolic $<85 \mathrm{mmHg}$; abnormal: systolic $\geq 130 \mathrm{mmHg}$ and diastolic $85 \mathrm{mmHg}$

Table 2 Odds ratio for being depression by metabolic syndrome and each of its components and SES (primarily education level and household income)

\begin{tabular}{|c|c|c|c|c|c|c|}
\hline \multirow[t]{2}{*}{ Characteristics } & \multicolumn{2}{|c|}{ Model1* } & \multicolumn{2}{|c|}{ Model2† } & \multicolumn{2}{|c|}{ Model3 } \\
\hline & OR(95\% CI) & p-value & OR(95\% CI) & p-value & $\mathrm{OR}(95 \% \mathrm{CI})$ & p-value \\
\hline \multicolumn{7}{|l|}{ Waist circumference (cm) } \\
\hline$<90$ (<80 for women) & 1.00 & 0.0002 & 1.00 & 0.18 & 1.00 & 0.10 \\
\hline$\geq 90$ ( $\geq 80$ for women) & \multicolumn{2}{|c|}{$1.49(1.21-1.82)$} & \multicolumn{2}{|c|}{$1.21(0.92-1.60)$} & \multicolumn{2}{|c|}{$1.30(0.95-1.78)$} \\
\hline \multicolumn{7}{|l|}{ Triglyceride level (mg/dL) } \\
\hline$<150$ & 1.00 & $<.0001$ & 1.00 & 0.02 & 1.00 & 0.09 \\
\hline$\geq 150$ & \multicolumn{2}{|c|}{$1.61(1.27-.2 .03)$} & \multicolumn{2}{|c|}{$1.35(1.06-1.71)$} & \multicolumn{2}{|c|}{$1.26(0.97-1.65)$} \\
\hline \multicolumn{7}{|l|}{ Blood pressure ${ }^{a}$} \\
\hline Normal & 1.00 & 0.42 & 1.00 & 0.13 & 1.00 & 0.32 \\
\hline Abnormal & \multicolumn{2}{|c|}{$0.90(0.70-1.16)$} & \multicolumn{2}{|c|}{$0.82(0.63-1.06)$} & \multicolumn{2}{|c|}{$0.87(0.65-1.15)$} \\
\hline \multicolumn{7}{|l|}{ HDL cholesterol level (mg/dL) } \\
\hline$\geq 40$ ( $\geq 50$ for women) & 1.00 & $<.0001$ & 1.00 & 0.003 & 1.00 & 0.0004 \\
\hline$<40$ (<50 for women) & \multicolumn{2}{|c|}{$1.52(1.25-.1 .86)$} & \multicolumn{2}{|c|}{$1.40(1.12-1.74)$} & \multicolumn{2}{|c|}{$1.55(1.22-1.99)$} \\
\hline \multicolumn{7}{|l|}{$\mathrm{FBS}(\mathrm{mg} / \mathrm{dL})$} \\
\hline$<100$ & 1.00 & 0.01 & 1.00 & 0.11 & 1.00 & 0.09 \\
\hline$\geq 100$ & \multicolumn{2}{|c|}{$1.36(1.07-1.73)$} & \multicolumn{2}{|c|}{$1.23(0.95-1.58)$} & \multicolumn{2}{|c|}{$1.26(0.96-1.65)$} \\
\hline \multicolumn{7}{|l|}{ Metabolic syndrome } \\
\hline No & 1.00 & $<.0001$ & 1.00 & 0.02 & 1.00 & 0.003 \\
\hline Yes & \multicolumn{2}{|c|}{$1.65(1.30-2.09)$} & \multicolumn{2}{|c|}{$1.34(1.05-1.72)$} & \multicolumn{2}{|c|}{$1.51(1.15-1.98)$} \\
\hline \multicolumn{7}{|l|}{ Education level } \\
\hline College or more & 1.00 & $<.0001$ & 1.00 & $<.0001$ & 1.00 & $<.0001$ \\
\hline High school & \multicolumn{2}{|c|}{$2.10(1.60-2.79)$} & \multicolumn{2}{|c|}{$1.77(1.34-2.33)$} & $1.52(1.13-2$ & \\
\hline Middle schools & $4.02(2.76-5$ & 37) & $2.86(1.93-4$ & 24) & $2.73(1.79-4$ & \\
\hline Elementary school or less & 6.20 & 2) & $3.72(2.49-5$ & 54) & $3.16(2.06-4$ & 35) \\
\hline House income & & & & & & \\
\hline High & 1.00 & $<.0001$ & 1.00 & $<.0001$ & 1.00 & $<.0001$ \\
\hline Middle & $1.73(1.35-2$ & 23) & $1.33(1.02-1$ & 72) & $1.45(1.09-1$ & 4) \\
\hline Low & $4.66(3.42-6$ & 36) & $2.54(1.84-3$ & 51) & $2.95(2.05-4$ & 4) \\
\hline
\end{tabular}

*Model1: adjusted for age.

†Model2: adjusted for age, education level, income, marital status, moderate physical activity more than, smoking status, alcohol consumption, prevalence of chronic diseases.

¥Model3: adjusted for age, education level, income, marital status, moderate physical activity more than, smoking status, alcohol consumption, prevalence of chronic diseases, history of depression.

Table 3 Odds ratio for being depression by metabolic syndrome and each of its components and SES (primarily education level and household income) in male and female 


\begin{tabular}{|c|c|c|c|c|c|c|c|c|c|c|c|c|}
\hline \multirow{3}{*}{ Characteristics } & \multicolumn{6}{|c|}{ Male } & \multicolumn{6}{|c|}{ Female } \\
\hline & \multicolumn{2}{|c|}{ Model1* } & \multicolumn{2}{|c|}{ Model2† } & \multicolumn{2}{|c|}{ Model3 } & \multicolumn{2}{|c|}{ Model1* } & \multicolumn{2}{|c|}{ Model2† } & \multicolumn{2}{|c|}{ Model3 } \\
\hline & $\begin{array}{c}\text { OR } \\
(95 \% \\
\text { CI })\end{array}$ & p-value & $\begin{array}{c}\text { OR } \\
(95 \% \\
\text { CI })\end{array}$ & $\mathrm{p}$-value & $\begin{array}{l}\text { OR } \\
(95 \% \\
\text { CI) }\end{array}$ & p-value & $\begin{array}{c}\text { OR } \\
(95 \% \\
\text { CI })\end{array}$ & p-value & $\begin{array}{c}\text { OR } \\
(95 \% \\
\text { CI })\end{array}$ & p-value & $\begin{array}{c}\text { OR } \\
(95 \% \\
\text { CI) }\end{array}$ & p-value \\
\hline \multicolumn{13}{|c|}{ Waist circumference $(\mathrm{cm})$} \\
\hline $\begin{array}{l}<90 \quad(<80 \\
\text { for women })\end{array}$ & 1.00 & 0.75 & 1.00 & 0.92 & 1.00 & 0.43 & 1.00 & $<.0001$ & 1.00 & 0.03 & 1.00 & 0.004 \\
\hline $\begin{array}{l}\geq 90 \quad(\quad \geq 80 \\
\text { for women })\end{array}$ & \multirow{2}{*}{\multicolumn{2}{|c|}{$\begin{array}{c}1.08(0.67- \\
1.48) \\
1(\mathrm{mq} / \mathrm{dL})\end{array}$}} & \multicolumn{2}{|c|}{$\begin{array}{c}0.97(0.57- \\
1.67)\end{array}$} & \multicolumn{2}{|c|}{$\begin{array}{c}0.78(0.42- \\
1.44)\end{array}$} & \multicolumn{2}{|c|}{$\begin{array}{c}1.70(1.36- \\
2.14)\end{array}$} & \multicolumn{2}{|c|}{$\begin{array}{c}1.46(1.05- \\
2.04)\end{array}$} & \multicolumn{2}{|c|}{$\begin{array}{c}1.78(1.20- \\
2.63)\end{array}$} \\
\hline \multicolumn{11}{|c|}{ Triglyceride level (mg/dL) } & & \\
\hline$<150$ & 1.00 & 0.02 & 1.00 & 0.01 & 1.00 & 0.15 & 1.00 & 0.0004 & 1.00 & 0.07 & 1.00 & 0.16 \\
\hline$\geq 150$ & \multicolumn{2}{|c|}{$\begin{array}{c}1.66(1.09- \\
2.53)\end{array}$} & \multicolumn{2}{|c|}{$\begin{array}{c}1.77(1.13- \\
2.76)\end{array}$} & \multicolumn{2}{|c|}{$\begin{array}{c}1.45(0.88- \\
2.39)\end{array}$} & \multicolumn{2}{|c|}{$\begin{array}{c}1.63(1.24- \\
2.13)\end{array}$} & \multicolumn{2}{|c|}{$\begin{array}{c}1.30(0.98- \\
1.73)\end{array}$} & \multicolumn{2}{|c|}{$\begin{array}{c}1.25(0.91- \\
1.70)\end{array}$} \\
\hline \multicolumn{13}{|l|}{ Blood pressure $^{a}$} \\
\hline Normal & 1.00 & 0.23 & 1.00 & 0.24 & 1.00 & 0.32 & 1.00 & 0.93 & 1.00 & 0.45 & 1.00 & 0.76 \\
\hline Abnormal & \multicolumn{2}{|c|}{$\begin{array}{c}0.76(0.48- \\
1.20)\end{array}$} & \multicolumn{2}{|c|}{$\begin{array}{c}0.76(0.48- \\
1.21)\end{array}$} & \multicolumn{2}{|c|}{$\begin{array}{c}0.77(0.46- \\
1.29)\end{array}$} & \multicolumn{2}{|c|}{$\begin{array}{c}1.02(0.75- \\
1.38)\end{array}$} & $\begin{array}{r}0.8 \\
1\end{array}$ & $\begin{array}{l}(0.65- \\
22)\end{array}$ & $\begin{array}{r}0.95 \\
1\end{array}$ & $\begin{array}{l}(0.68- \\
32)\end{array}$ \\
\hline HDL cholesterol & level $(n$ & $\mathrm{g} / \mathrm{dL})$ & & & & & & & & & & \\
\hline $\begin{array}{l}\geq 40 \quad(\quad \geq 50 \\
\text { for women })\end{array}$ & 1.00 & 0.05 & 1.00 & 0.22 & 1.00 & 0.09 & 1.00 & 0.0002 & 1.00 & 0.002 & 1.00 & 0.001 \\
\hline $\begin{array}{l}<40 \quad(<50 \\
\text { for women })\end{array}$ & $\begin{array}{r}1.53 \\
2\end{array}$ & $\begin{array}{l}(1.00- \\
35)\end{array}$ & $\begin{array}{r}1.34 \\
2\end{array}$ & $\begin{array}{l}(0.84- \\
16)\end{array}$ & $\begin{array}{r}1.59 \\
2\end{array}$ & $\begin{array}{l}(0.94- \\
68)\end{array}$ & $\begin{array}{r}1.52 \\
1\end{array}$ & $\begin{array}{l}(1.22- \\
90)\end{array}$ & $\begin{array}{r}1.4 \\
1\end{array}$ & $\begin{array}{l}(1.16- \\
86)\end{array}$ & $\begin{array}{r}1.57 \\
2\end{array}$ & $\begin{array}{l}(1.20- \\
04)\end{array}$ \\
\hline $\mathrm{FBS}(\mathrm{mg} / \mathrm{dL})$ & & & & & & & & & & & & \\
\hline$<100$ & 1.00 & 0.27 & 1.00 & 0.33 & 1.00 & 0.13 & 1.00 & 0.02 & 1.00 & 0.27 & 1.00 & 0.43 \\
\hline$\geq 100$ & $\begin{array}{r}1.29 \\
2\end{array}$ & $\begin{array}{l}(0.82- \\
04)\end{array}$ & $\begin{array}{r}1.29 \\
2\end{array}$ & $\begin{array}{l}(0.78- \\
12)\end{array}$ & $\begin{array}{r}1.50 \\
2\end{array}$ & $\begin{array}{l}(0.89- \\
53)\end{array}$ & $\begin{array}{r}1.39 \\
1\end{array}$ & $\begin{array}{l}(1.06- \\
83)\end{array}$ & $\begin{array}{r}1.18 \\
1\end{array}$ & $\begin{array}{l}(0.88- \\
57)\end{array}$ & $\begin{array}{r}1.14 \\
1\end{array}$ & $\begin{array}{l}(0.83- \\
57)\end{array}$ \\
\hline Metabolic syndr & me & & & & & & & & & & & \\
\hline No & 1.00 & 0.08 & 1.00 & 0.11 & 1.00 & 0.10 & 1.00 & $<.0001$ & 1.00 & 0.03 & 1.00 & 0.01 \\
\hline Yes & $\begin{array}{r}1.51 \\
2\end{array}$ & $\begin{array}{l}(0.95- \\
38)\end{array}$ & $\begin{array}{r}1.49 \\
2\end{array}$ & $\begin{array}{l}(0.92- \\
42)\end{array}$ & $\begin{array}{r}1.58 \\
2\end{array}$ & $\begin{array}{l}(0.92- \\
71)\end{array}$ & $\begin{array}{r}1.76 \\
2\end{array}$ & $\begin{array}{l}(1.35- \\
29)\end{array}$ & 1.4 & $\begin{array}{l}(1.04- \\
87)\end{array}$ & $\begin{array}{r}1.55 \\
2\end{array}$ & $\begin{array}{l}(1.13- \\
13)\end{array}$ \\
\hline Education level & & & & & & & & & & & & \\
\hline $\begin{array}{l}\text { College or } \\
\text { more }\end{array}$ & 1.00 & 0.01 & 1.00 & $<.0001$ & 1.00 & $<.0001$ & 1.00 & $<.0001$ & 1.00 & 0.01 & 1.00 & 0.06 \\
\hline High school & $\begin{array}{r}2.50 \\
4\end{array}$ & $\begin{array}{l}(1.32- \\
92)\end{array}$ & $\begin{array}{r}2.18 \\
4\end{array}$ & $\begin{array}{l}(1.14- \\
16)\end{array}$ & $\begin{array}{r}2.17 \\
4\end{array}$ & $\begin{array}{l}(1.08- \\
36)\end{array}$ & $\begin{array}{r}1.91 \\
2\end{array}$ & $\begin{array}{l}(1.42- \\
57)\end{array}$ & 1.5 & $\begin{array}{l}(1.14- \\
09)\end{array}$ & $\begin{array}{r}1.36 \\
1\end{array}$ & $\begin{array}{l}(0.98- \\
89)\end{array}$ \\
\hline $\begin{array}{l}\text { Middle } \\
\text { schools }\end{array}$ & $\begin{array}{r}6.94 \\
14\end{array}$ & $\begin{array}{l}(3.26- \\
.77)\end{array}$ & $\begin{array}{r}4.75 \\
9\end{array}$ & $\begin{array}{l}(2.29- \\
84)\end{array}$ & $\begin{array}{r}7.36 \\
16\end{array}$ & $\begin{array}{l}(3.33- \\
30)\end{array}$ & $\begin{array}{r}3.17 \\
4\end{array}$ & $\begin{array}{l}(2.02- \\
98)\end{array}$ & $\begin{array}{r}2.08 \\
3\end{array}$ & $\begin{array}{l}(1.30- \\
34)\end{array}$ & $\begin{array}{r}1.90 \\
3\end{array}$ & $\begin{array}{l}(1.15- \\
14)\end{array}$ \\
\hline $\begin{array}{l}\text { Elementary } \\
\text { school or } \\
\text { less }\end{array}$ & $\begin{array}{r}16.8 \\
34\end{array}$ & $\begin{array}{l}(8.12- \\
.79)\end{array}$ & $\begin{array}{r}10.9 \\
22\end{array}$ & $\begin{array}{l}(5.24- \\
.85)\end{array}$ & $\begin{array}{r}10.78 \\
24\end{array}$ & $\begin{array}{l}(4.73- \\
61)\end{array}$ & $\begin{array}{r}4.07 \\
6\end{array}$ & $\begin{array}{l}(2.63- \\
30)\end{array}$ & $\begin{array}{r}2.26 \\
3\end{array}$ & $\begin{array}{l}(1.41- \\
60)\end{array}$ & $\begin{array}{r}1.93 \\
3\end{array}$ & $\begin{array}{l}(1.15- \\
24)\end{array}$ \\
\hline House income & & & & & & & & & & & & \\
\hline High & 1.00 & $<.0001$ & 1.00 & $<.0001$ & 1.000 & $<.0001$ & 1.00 & $<.0001$ & 1.00 & $<.0001$ & 1.00 & $<.0001$ \\
\hline Middle & $\begin{array}{r}1.45 \\
2\end{array}$ & $\begin{array}{l}(0.85- \\
46)\end{array}$ & $\begin{array}{r}0.98 \\
1\end{array}$ & $\begin{array}{l}(0.56- \\
71)\end{array}$ & $\begin{array}{r}0.91 \\
1\end{array}$ & $\begin{array}{l}(0.49- \\
71)\end{array}$ & $\begin{array}{r}1.83 \\
2\end{array}$ & $\begin{array}{l}(1.39- \\
41)\end{array}$ & $\begin{array}{r}1.4 \\
1\end{array}$ & $\begin{array}{l}(1.10- \\
95)\end{array}$ & $\begin{array}{r}1.71 \\
2\end{array}$ & $\begin{array}{l}(1.24- \\
35)\end{array}$ \\
\hline Low & $\begin{array}{r}7.07 \\
12 \\
\end{array}$ & $\begin{array}{l}(4.01- \\
.46)\end{array}$ & $\begin{array}{r}2.82 \\
5 \\
\end{array}$ & $\begin{array}{l}(1.57- \\
06)\end{array}$ & $\begin{array}{r}2.79 \\
5 \\
\end{array}$ & $\begin{array}{l}(1.46- \\
34)\end{array}$ & $\begin{array}{r}3.75 \\
5 \\
\end{array}$ & $\begin{array}{l}(2.66- \\
28)\end{array}$ & $\begin{array}{r}2.25 \\
3\end{array}$ & $\begin{array}{l}(1.56- \\
26)\end{array}$ & $\begin{array}{r}2.65 \\
4 \\
\end{array}$ & $\begin{array}{l}(1.72- \\
10)\end{array}$ \\
\hline
\end{tabular}

*Model1: adjusted for age.

†Model2: adjusted for age, education level, income, marital status, moderate physical activity more than, smoking status, alcohol consumption, prevalence of chronic diseases.

$\ddagger$ Model3: adjusted for age, education level, income, marital status, moderate physical activity more than, smoking status, alcohol consumption, prevalence of chronic diseases, history of depression. 
Table 4 Combined effects of metabolic syndrome and SES (primarily education level and household income) for depression in male and female

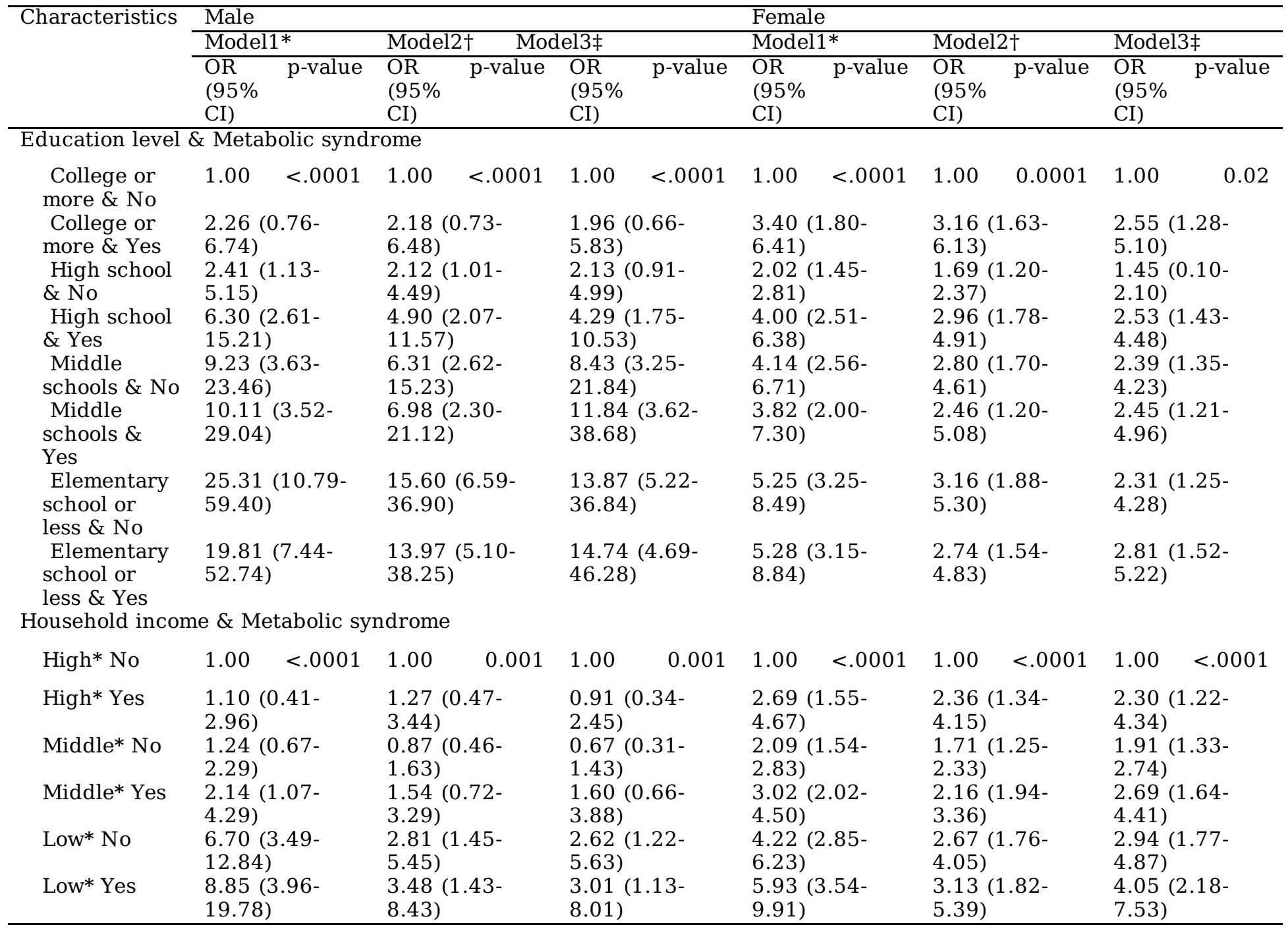

*Model1: adjusted for age.

†Model2: adjusted for age, education level, income, marital status, moderate physical activity more than, smoking status, alcohol consumption, prevalence of chronic diseases.

$¥$ Model3: adjusted for age, education level, income, marital status, moderate physical activity more than, smoking status, alcohol consumption, prevalence of chronic diseases, history of depression.

\section{Additional File}

Additional file 1: Table S1. Odds ratio(95\% CI) and interactive effects of metabolic syndrome and SES (primarily education level and household income) on depression. The data information in this additional file serves as supplementary materials to the study.

Figures 


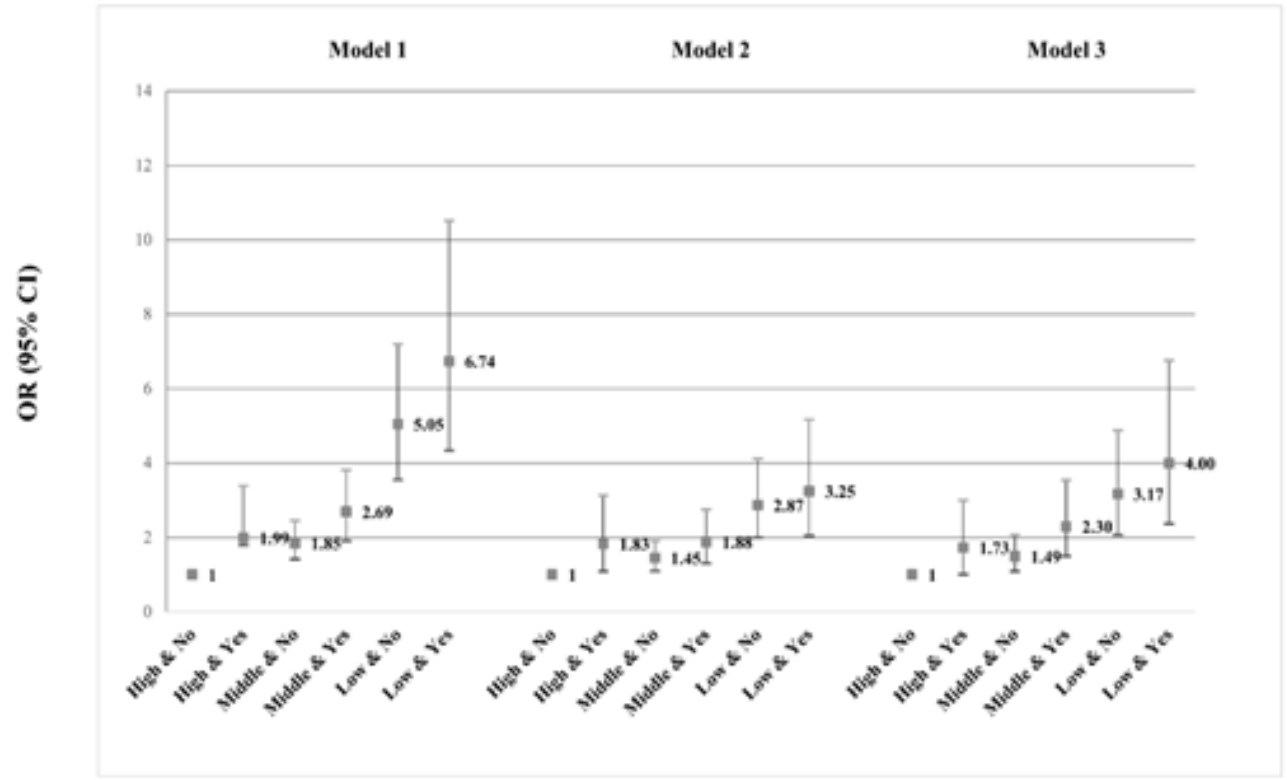

(A) Household income $\&$ Metabolic syndrome

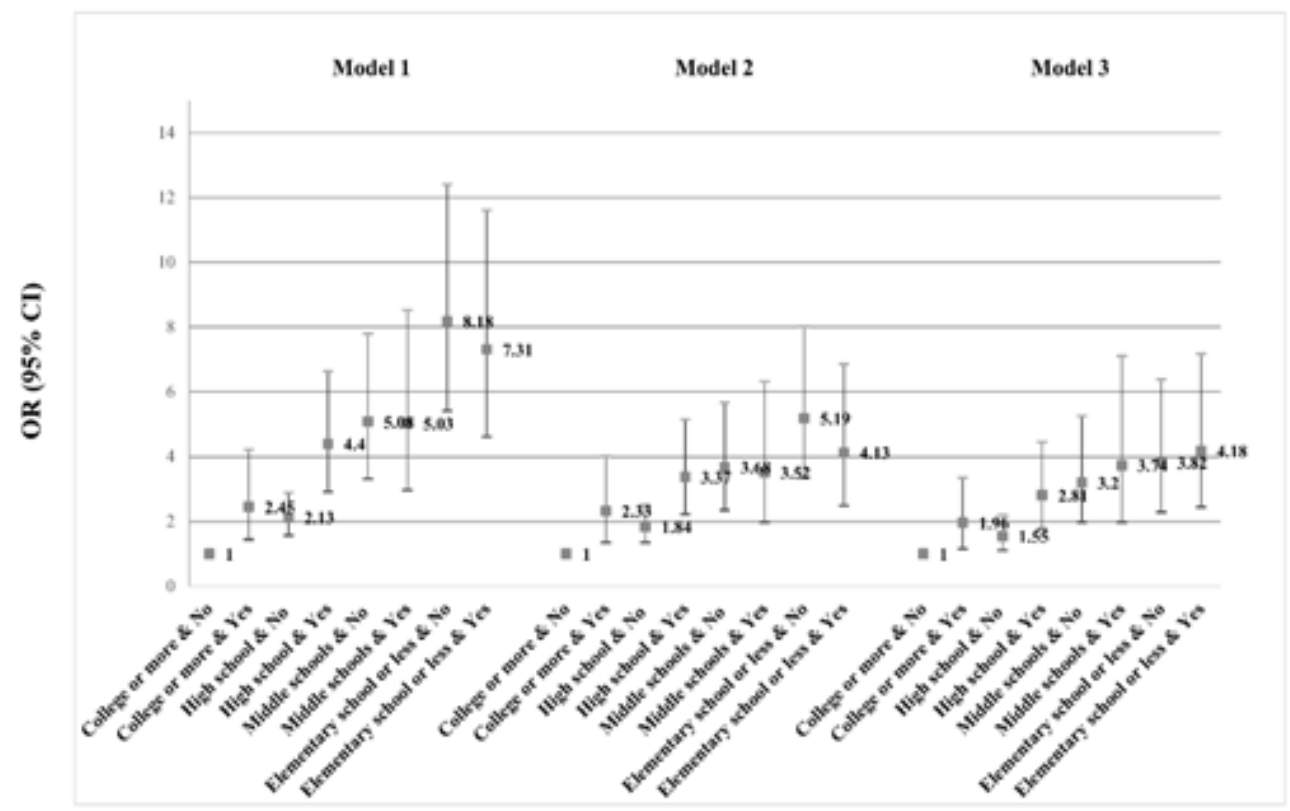

(B) Education level \& Metabolic syndrome

\section{Figure 1}

Combined effects of metabolic syndrome and SES for depression. (A) Household income and Metabolic syndrome (B) Primarily Education level and Metabolic syndrome Model1: adjusted for gender, age. Model2: adjusted for gender, age, education level, income, marital status, moderate physical activity more than, smoking status, alcohol consumption, prevalence of chronic diseases. Model3: adjusted for gender, age, education level, income, marital status, moderate physical activity more than, smoking status, alcohol consumption, prevalence of chronic diseases, history of depression 


\section{Supplementary Files}

This is a list of supplementary files associated with this preprint. Click to download.

- supplementary.docx 